\title{
LINFADENOPATÍA POR SILICONA EN UNA PACIENTE CON PRÓTESIS MAMARIAS
}

\section{Silicone-induced lymphadenopathy in a patient suffering firom mammary prosthesis: a case report}

Germán García-Soto, M.D.*, Jorge Castaño, M.D.**, Ronald Smith-Meneses, M.D.***

Recibido: febrero 17/06 - Revisado: marzo 31/06 - Aceptado: mayo 24/06

\section{RESUMEN}

Se presenta el caso de una mujer de 47 años, con adenopatías axilares izquierdas, sin antecedentes médicos y a quien se le habían colocado implantes mamarios 8 años antes con fines estéticos. Se realizó resección ganglionar y la patología reportó células gigantes multinucleadas tipo cuerpo extraño, con abundantes vacuolas citoplasmáticas y linfocitos polimorfonucleares con lo que se estableció el diagnóstico de adenopatía por silicona y se procedió a la remoción y cambio de la prótesis.

La biopsia por aspiración con aguja fina (BACAF) de los ganglios linfáticos que drenan el sitio donde se localiza la prótesis puede hacer el diagnóstico de linfadenopatía por silicona y a la vez permite descartar la presencia de un proceso maligno que pudiera coincidir en algunas pacientes.

Palabras clave: linfadenopatía, elastómeros de silicona, prótesis mamarias, biopsia por aspiración con aguja fina.

\footnotetext{
* Ginecólo-Oncólogo, Profesor de Oncología Ginecológica. Universidad de Antioquia. Hospital Universitario San Vicente de Paúl. Calle 64 carrera 51D- Medellín. Correo electrónico: gegar65@yahoo.com

** Patólogo, Profesor de Patología, Universidad de Antioquia.

*** Residente de 3er año, Ginecología y Obstetricia. Universidad de Antioquia.
}

\section{SUMMARY}

This is a case report of a 47-year old woman having no antecedents of disease, but a surgical history of silicone breast-implants 8 years beforehand. The patient's complaint concerned the left axillary lymph nodes. A ganglion resection was done and fine needle aspiration biopsy (FNAB) revealed giant multinucleated cells having abundant cytoplasmatic vacuoles and polymorphonuclear lymphocytes leading to a diagnosis of siliconinduced adenopathy. The prosthesis was then removed and changed. Lymph node FNAB is able to diagnose silicone lymphadenopathy and excludes malignant neoplasm.

Key words: lymphadenopathy, silicone elastomers, breast implants, fine needle aspiration biopsy.

\section{INTRODUCCIÓN}

La linfadenopatía por silicona es una entidad cuya incidencia y prevalencia se desconoce debido a su rareza. Es explicada por la ruptura de la prótesis de silicona o por filtraciones o escapes de la cubierta de una prótesis intacta. Debe hacerse el diagnóstico diferencial principalmente con cáncer de mama. La biopsia por aspiración con aguja fina y la resonancia nuclear magnética (RNM) confirman el diagnóstico. 


\section{PRESENTACIÓN DEL CASO}

Paciente de sexo femenino quien consultó por cuadro de 1 mes de evolución de aumento de volumen en los ganglios axilares izquierdos acompañados de rubor, calor y eritema local con dolor a la movilización del brazo izquierdo y a la palpación. No presentó secreción.

De su historia ginecobstétrica se destaca que es una mujer nulípara y que no había usado terapia de reemplazo hormonal. No presentaba antecedentes familiares de cáncer de mama. Se le habían colocado implantes mamarios con carácter estético 8 años atras. En el examen físico se encontró la presencia de tres ganglios en la axila izquierda entre 2 y $3 \mathrm{~cm}$ de diámetro mayor, móviles, no adheridos a planos profundos, de consistencia dura y no se encontraron lesiones palpables en ninguna de las glándulas mamarias.

Las radiografías de tórax (figuras 1 y 2), la mamografía (figura 3) y la ecografía fueron normales.

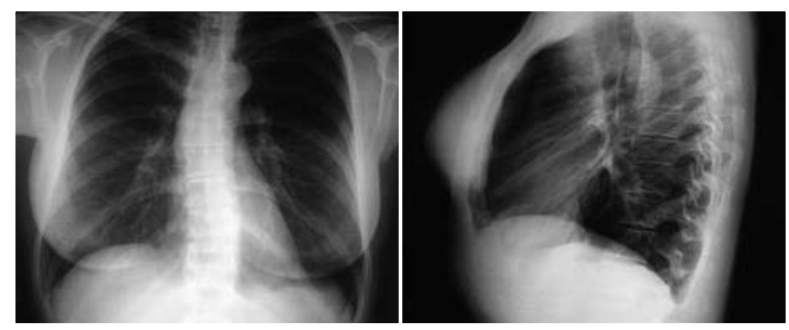

Figuras 1 y 2: Radiografía de tórax PA y Lateral que muestra las prótesis mamarias en buen estado y sin signos de filtración.

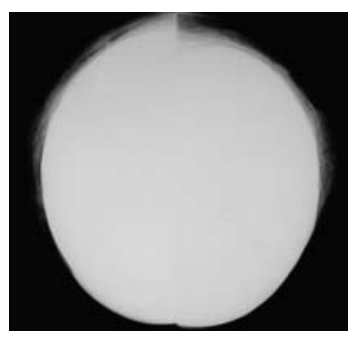

Figura 3: Mamografía bilateral proyección cráneocaudal normal, sin signos radiológicos de filtración.

Se inició manejo médico con antiinflamatorios sin resultados satisfactorios. Se procedió entonces a la resección del complejo ganglionar. A los ocho días post-operatorio la paciente presenta nueva- mente una masa en la misma localización y con las mismas características de la inicial motivo por el cual se decide la remoción y el cambio de prótesis. Se informa que se encuentra una pequeña filtración en la prótesis izquierda.

En el laboratorio de patología se recibieron dos ganglios linfáticos de 2 y 3,5 cm de diámetro, al corte, color crema homogéneo y una placa de extendido, producto de biopsia por aspiración con aguja fina de ganglio linfático. Fueron procesados según los métodos de rutina y los preparados histológicos y citológicos fueron teñidos con hematoxilina-eosina.

El estudio microscópico del extendido producto de la biopsia por aspiración reveló un fondo de material eosinófilo amorfo, con bastantes linfocitos maduros, macrófagos espumosos y numerosas células gigantes multinucleadas de tipo cuerpo extraño, con vacuolas fagocíticas en su citoplasma.

El estudio del tejido de ganglio linfático demostró una severa alteración de la arquitectura con infiltración por numerosos macrófagos y células gigantes multinucleadas, con notable vacuolización del citoplasma.

Estos hallazgos corresponden a una inflamación crónica granulomatosa secundaria a cuerpo extraño. La presencia de infiltrado inflamatorio linfoide, numerosos macrófagos espumosos y células gigantes multinucleadas de tipo cuerpo extraño, con vacuolas fagocíticas de diámetro variable, incluyendo espacios de aspecto quístico, ha sido descrita previamente y se relaciona con la fagocitosis de partículas de silicona. (figuras 4, 5 y 6 )

Con este resultado se hizo el diagnóstico de linfadenopatía por cuerpo extraño.

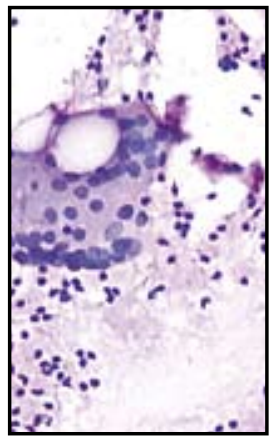

Figura 4: Extendido producto de biopsia por aspiración de ganglio linfático: fondo de material eosinófilo amorfo, con numerosos linfocitos maduros y macrófagos espumosos. Se identifica una célula gigante multinucleada de tipo a cuerpo extraño, con vacuolas fagocíticas en su citoplasma. (Coloración de Hematoxilina-Eosina, 20X). 


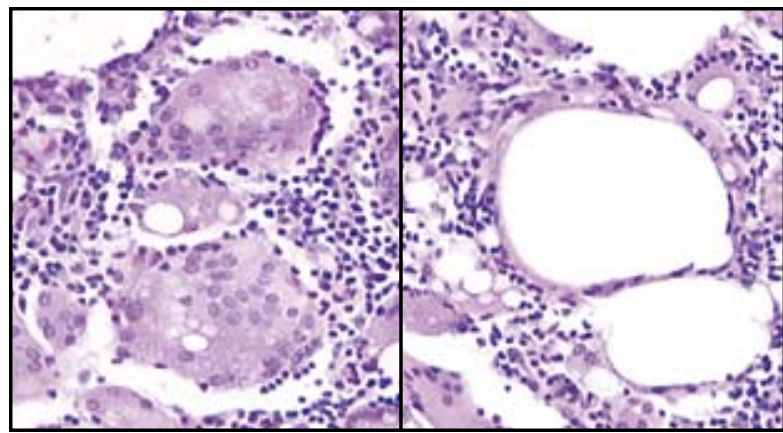

Figuras 5 y 6: Tejido de ganglio linfático: severa alteración de la arquitectura con infiltración por numerosos macrófagos y células gigantes multinucleadas, con notable vacuolización del citoplasma (Hematoxilina-Eosina, 400X).

\section{DISCUSIÓN}

Las prótesis mamarias se utilizan desde hace tiempo con fines estéticos y en cirugía reconstructiva. La linfadenopatía por silicona (también llamada siliconoma) es una entidad clínica que se ha descrito en pacientes que han recibido prótesis en diferentes localizaciones del cuerpo-siendo las mamas, los glúteos y las articulaciones los sitios preferidos-y que se caracteriza por el compromiso de ganglios regionales y/o sistémicos. ${ }^{1-3}$

Siendo una entidad rara, se produce por una reacción de tipo cuerpo extraño a la presencia de silicona debido a la ruptura o a la filtración inadvertida del material proveniente de una prótesis o a la inyección local, procedimiento que en la mayoría de las veces es de forma ilegal. ${ }^{1,4,5}$ La adenopatía puede presentarse generalmente entre los 4 y 10 años posteriores al implante pero hay reportes que los sitúan hasta 20 años después. ${ }^{6,7}$

La incidencia y la prevalencia real de la entidad son desconocidas en el total de la población de mujeres con implantes debido a que la mayoría de la literatura se refiere a reportes de casos individuales o a situaciones estimuladas por entidades clínicas específicas. ${ }^{4}$

Se ha encontrado este tipo de reacción en sitios tan distantes y exóticos como la cara (surco naso-labial), músculos temporales, nariz, hombros, codos, tórax, pleura y pared abdominal y aún en el cerebro. ${ }^{1-4,6,8}$
El cuadro clínico característico es el de una paciente que consulta por mastalgia en el lado afectado, uno o varios ganglios aumentados de tamaño, móviles, de consistencia intermedia a dura, no adheridos a planos profundos. Se puede encontrar además eritema, calor, rubor y en casos avanzados ulceración con infección secundaria principalmente por Staphylococcus aureus. ${ }^{1,2,4}$ Por lo general, no se encuentran lesiones palpables en mamas y si las hubiera deberá hacerse todo lo posible por descartar un cáncer mamario. ${ }^{1-3}$

Los sitios distintos de la mama que con más frecuencia producen metástasis en los ganglios linfáticos axilares incluyen predominantemente el melanoma y también cáncer de tiroides, riñón, pulmón, estómago e hígado. ${ }^{9}$ Debe considerarse también la posibilidad de linfomas, las infecciones de extremidades superiores y la brucelosis. ${ }^{10}$ Algunas veces puede ser difícil diferenciar entre una linfadenopatía por silicona y una metástasis ganglionar maligna debido a que en la primera patología puede encontrarse nodularidad, retracción cutánea, inversión del pezón y masas de consistencia firme que podrían simular un proceso neoplásico. ${ }^{1-3}$

Dentro de la presentación clínica debe tenerse en cuenta también el llamado "síndrome silicona" que incluye disnea, fiebre, tos, hemoptisis, dolor en el pecho, hipoxia, hemorragia alveolar y alteraciones de la conciencia, es decir, una presentación similar a un embolismo graso, entidad con la cual debe hacerse diagnóstico diferencial sobre todo en su presentación aguda. ${ }^{5}$

El diagnóstico se hace entonces con base en:

1. Una buena historia clínica teniendo presente el antecedente importante de la mamoplastia de aumento.

2. Un examen físico completo haciendo énfasis en las características de la(s) masa(s).

3. Una biopsia por aspiración con aguja fina (BACAF) que característicamente mostrará abundantes células gigantes multinucleadas tipo cuerpo extraño, vacuolas citoplasmáticas conte- 
niendo material homogéneo, no birrefringente y linfocitos polimorfonucleares. ${ }^{1,3}$

4. Finalmente una Resonancia Magnética Nuclear (RMN) con una secuencia selectiva (Invertion Recovery)-que suprime toda señal que no sea silicona (piel, grasa, tejido mamario y agua) - mostrará la extensión del compromiso glandular y la presencia o no de colecciones de silicona y adicionalmente descartará otras patologías asociadas. $^{2,11-13}$

El tratamiento debe ser el cambio de la(s) prótesis afectada(s) en los casos sin complicaciones pero si el diagnóstico pasa inadvertido o es tardío podría incluso ser necesaria una mastectomía total principalmente en las presentaciones en las cuales se encuentre una destrucción local pero extensa del tejido, ulceración con sobreinfección, cicatrices, deformidad y daño neural. ${ }^{2}$

\section{AGRADECIMIENTOS}

Al doctor Juan Guillermo Londoño Cardona, Jefe del departamento de Ginecología y Obstetricia de la Universidad de Antioquia, al doctor Ignacio Velásquez Ceballos, médico internista y al doctor Fernando Gutiérrez Mendoza, patólogo de la Clínica Las Vegas por su valiosa colaboración en este escrito.

\section{REFERENCIAS}

1. Morales-Ferrer G, Duarte-Torres RM. Linfadenopatía por silicón en una paciente con prótesis mamaria. Reporte citológico de un caso. Rev Med Hosp Gen Méx 2004;67:208-10.

2. Gutiérrez L, Montes A. Siliconomas: Caso clínico. Rev Méd Chile 2002;130:793-4.
3. Santos-Briz A Jr, Lopez-Rios F, Santos-Briz A, De Agustin PP. Granulomatous reaction to silicone in axilary limph nodes. A case report with cytologic findings. Acta cytologic 1999;43:1163-5.

4. Austad ED. Breast implant-related silicone granulomas: the literature and the litigation. Plast Reconstr Surg 2002;109:1724-30.

5. Schmid A, Tzur A, Leshko L, Krieger BP. Silicone embolims syndrome: a case report, review of the literature, and comparison with fat embolism syndrome. Chest 2005;127:2276-81.

6. Vaamonde R, Cabrera JM, Vaamonde-Martin RJ, Jimena I, Marcos Matin J. Silicone granulomatous lymphadenopathy and siliconomas of the breast. Histology Histopathol 1997;12:1003-11.

7. Chen TH. Silicone injection granulomas of the breast: treatment by subcutaneous mastectomy and immediate subpectoral breast implant. Br J Plast Surg 1995;48:71-6.

8. Levine RL, Allen TC, Cartwrigth J Jr, Cagle PT. Silicone thorax due to a ruptured breast implant. Chest 2005;127:1854-7.

9. Tench D, Page D. Tumor primario desconocido que se presenta con adenopatía axilar. En: Copeland E. La mama, manejo multidisciplinario de las enfermedades benignas y malignas. Editorial Medica Panamericana; 2000. p. 1469-73.

10. Haynes B. Adenomegalias y esplenomegalia. En: Harrison. Principios de Medicina Interna. 12 edición. México: Editorial Interamericana; 1991. p. 419-25.

11. Holmich LR, Vejborg I, Conrad C, Sletting S, McLaughlin JK.The diagnosis of breast implant rupture: MRI findings compared with findings at explantation. Eur J Radiol 2005;53:213-25.

12. Holmich LR, Vejborg I, Conrad C, Sletting S, HoierMadsen M, Fryzek JP, et al. Untreated silicone breast implant rupture. Plast Reconstr Surg 2004;114: 204-14.

13. Scaranello AM, Marques AF,Smialowski EB,Lederman HM. Evaluation of the rupture of silicone breast implants by mamography, ultrasonography and magnetic resonance imaging in asymptomatic patients. Sao Paulo Med J 2004;122:41-7. 